\title{
Mental health of unemployed men in different parts of England and Wales
}

\author{
PAUL R JACKSON, PETER WARR
}

\begin{abstract}
In a study of mental health among unemployed men two contrasting hypotheses about the importance of the local unemployment rate were examined-namely, that very high local unemployment might be associated with either impoverishment or resilience of the community, which would affect health in opposite ways. The mental health of 954 unemployed men registered at 41 unemployment benefit offices in England and Wales was assessed by the general health questionnaire, men in areas of particularly high unemployment being compared with men in areas of moderate and relatively low unemployment. Scores for ill health were significantly lower in areas of particularly high unemployment, even when personal factors known to affect mental health during unemployment were controlled for.

These results support the hypothesis that communities with high rates of unemployment develop resilience that is beneficial for the mental health of the unemployed.
\end{abstract}

\section{Introduction}

In considering the influence of the local unemployment rate on the psychological impact of being unemployed two contrasting patterns have been proposed.' A positive association between local unemployment rate and mental ill health among unemployed people was suggested because high unemployment is often associated with adverse environmental conditions. Areas of long term high unemployment are also areas of widespread poverty and economic deprivation with high domestic overcrowding and poor quality of housing. ${ }^{2}$ On the other hand, a negative association between local unemployment rate and mental ill health might be expected because of the development of community resilience. Long term high local unemployment may give rise to stronger social support networks, greater material help, and institutional changes, which to some extent protect jobless people and their families. Unemployment may be viewed in these areas as less deviant and less a cause of social stigmatisation and low self esteem than in areas where joblessness is relatively rare.

We examined these contrasting possibilities by using as an index of mental health the 30 item general health questionnaire, a self administered screening test for detecting non-psychotic psychiatric disorder.

\section{Methods and results}

We gathered data from 954 unemployed men registered at 41 unemployment benefit offices in England and Wales. The distributions of age and length of unemployment were the same in all locations. ${ }^{3}$ Each site was, for analytical reasons, located within an area whose contemporary local unemployment rate was known from figures published in the Department of Employment Gazette. By this process of allocation we identified 34 areas for which unemployment rate and scores on the general health questionnaire could be examined.

There were in practice no areas of very low unemployment in the sample;

MRC/ESRC Social and Applied Psychology Unit, University of Sheffield, Sheffield S10 2TN

PAUL JACKSON, MSC, PHD, research fellow

PETER WARR, MA, PHD, director

Correspondence to: Dr Jackson. the five lowest rates ranged from $6 \cdot 6 \%$ to $10 \cdot 1 \%$. We therefore concentrated our analyses on regions of very high unemployment. As the north east of England and Merseyside have long been viewed as "unemployment black spots" respondents from those areas were defined as the criterion group to be compared with their counterparts in other regions. The other regions were divided into areas of moderate and relatively low unemployment.

The table shows the results. Mean scores on the general health questionnaire in all groups were substantially above those found in samples of employed people, in whom an average of around 19 is typical. ${ }^{4}$ One way analysis of variance indicated that the average score for the men from north east England and Merseyside was significantly lower $(p<0.001)$ than that for the two other groups, which did not differ from each other. (Mean values for north east England and Merseyside were similar: 31.74 and 32.30, respectively.) This pattern may have arisen, however, from differences in individual men rather than the communities. Personal factors known to be associated with mental health during unemployment are age, length of unemployment, family composition, and the importance of paid employment. ${ }^{1}$ To check whether these factors accounted for the observed regional difference we performed an analysis of covariance with them as covariates. The table shows the adjusted mean scores; the regional difference remained significant $(p<0 \cdot 01)$.

Mean scores for mental health from general health questionnaire of unemployed men in areas with different unemployment rates

\begin{tabular}{|c|c|c|c|}
\hline & $\begin{array}{l}\text { North east England } \\
\text { and Merseyside } \\
\quad(n=221)\end{array}$ & $\begin{array}{l}\text { Areas of moderate } \\
\text { unemployment } \\
(n=505)\end{array}$ & $\begin{array}{l}\text { Areas of lower } \\
\text { unemployment } \\
(\mathbf{n}=226)\end{array}$ \\
\hline $\begin{array}{l}\text { Median unemployment rate (\%) } \\
\text { Actual score } \\
\text { Adjusted score }\end{array}$ & $\begin{array}{l}18 \cdot 7 \\
31 \cdot 93 \\
32 \cdot 90\end{array}$ & $\begin{array}{l}14 \cdot 0 \\
36 \cdot 18 \\
36 \cdot 01\end{array}$ & $\begin{array}{l}10 \cdot 1 \\
37 \cdot 68 \\
36 \cdot 88\end{array}$ \\
\hline
\end{tabular}

\section{Discussion}

The greater material deprivation in Merseyside and the north east of England is known to be associated with increased mortality. This difference in the population overall persists when samples of unemployed people are studied: Moser et al found that for unemployed men seeking jobs in 1971 the standardised mortality ratio for the next decade was 141 in the north and west of England (and Wales) but 118 in the south and east of England. ${ }^{5}$

Our results suggest that communities in the north east of England and Merseyside have certain characteristics that give rise to better mental health in unemployed men than that found in other regions; these were important in addition to the four personal factors entered into our analysis. Thus community support in areas of long term high unemployment may to some extent protect unemployed men psychologically. The material deprivation that exists in these areas is, however, associated with a higher prevalence of poor physical health and premature death in unemployed as well as employed men. Furthermore, even in more favourable circumstances, unemployment remains associated with impaired mental health.

\section{References}

1 Warr PB. Work, unemployment, and mental health. Oxford: Oxford University Press, 1987. 2 Townsend $\mathrm{P}, \mathrm{Phillimore} \mathrm{P}, \mathrm{Beattie} A$. Inequalities in health in the Northern region. Newcastle upon Tyne: Northern Regional Health Authority, 1986.

3 Jackson PR, Warr PB. Unemployment and psychological ill-health: :he moderating role of duration and age. Psychol Med 1984;14:605-14.

$4 \mathrm{Warr}$ PB, Jackson PR. Factors influencing the psychological impact of prolonged unemployment and of re-employment. Psychol Med 1985;15:795-807.

5 Moser KA, Fox AJ, Jones DR, Goldblatt PO. Unemployment and mortality: further evidence from the OPCS longitudinal study 1971-81. Lancet 1986;i:365-7. 